\title{
Farmers' Market Use is Associated with Fruit and Vegetable Consumption Among Low-Income Populations: A Cross-Sectional Study from Southern Arizona
}

\author{
Halimatou $\mathrm{A}^{* 1}$, Navaugh $\mathrm{F}^{2}$, Kara $\mathrm{J}^{3}$ and Abigail $\mathrm{P}^{3}$ \\ ${ }^{1}$ Health Promotion Sciences Department, University of Arizona, Tucson, USA \\ ${ }^{2}$ Department of Nutritional Sciences, University of Arizona, Tucson, USA \\ ${ }^{3}$ Community Food Resource Center, Community Food Bank of Southern Arizona, Tucson, USA
}

${ }^{*}$ Corresponding author: Halimatou A, Health Promotion Sciences Department, University of Arizona, Tucson, USA, E-mail: halaofe@email.arizona.edu

Citation: Halimatou A, Navaugh F, Kara J, Abigail P (2017) Farmers' market use is associated with fruit and vegetable consumption among low-income populations: A cross-sectional study from Southern Arizona. J Nutr Health Sci 4(2): 201. doi: 10.15744/2393-9060.4.201

Received Date: April 04, 2017 Accepted Date: May 19, 2017 Published Date: May 22, 2017

\begin{abstract}
Background: While farmers' markets (FM) are a potential strategy to increase access to fruits and vegetables (F\&V), more information is needed regarding use of FM among low-income populations.

Objective: To examine socio-demographic characteristics and frequency of F\&V consumption of participants; barriers and facilitators to FM shopping and fruit and vegetable (F\&V) consumption; and associations between FM use with F\&V consumption in Southern Arizona.

Methods: Cross-sectional surveys were conducted with two groups of SNAP recipients in Pima County, AZ: 56 FM customers and 107 primary household food shoppers. All questionnaires assessed socio-demographic characteristics, food shopping patterns, barriers to and facilitators of FM shopping and F\&V consumption. Linear regression analyses determined the associations between FM use with $\mathrm{F} \& \mathrm{~V}$ consumption, controlling for age, race, education, and gender.

Results: Majority of FM customers were white, female, over 42 years of age and college graduate. Top three motivators to shopping included variety of products, fresh food, and convenient location. Common barriers to F\&V consumption were price, lack of nearby options, and lack of available healthy options. F\&V consumption was positively associated with use of farmers' markets.

Conclusions and Implications: Farmers' markets may be a viable method to increase produce consumption in low-income population. However, for these programs to be successful, barriers and facilitators to farmers' market shopping and F\&V consumption should be taken into account.
\end{abstract}

Keywords: Farmers' market; Fruit and vegetable consumption; low-income communities; AZ

\section{Introduction}

Fruit and vegetable $(\mathrm{F} \& \mathrm{~V})$ consumption is an important dietary component of disease prevention. Adults who consume more F\&V are less likely to develop heart disease, diabetes, and certain types of cancer and are more likely to sustain a healthy weight [13]. In the United States, substantial socioeconomic disparities exist in the prevalence of chronic diseases and the higher prevalence of unhealthy behaviors in lower socioeconomic groups help drive these disparities [4]. Several studies have consistently shown that low-income individuals consume fewer F\&V than higher income individuals [5-7]. Arizona is no exception since $21 \%$ of adults with an annual income of $\$ 15,000$ or less meet F\&V intake guidelines [8]. Studies have identified specific environmental and psychosocial barriers that may limit F\&V consumption among low-income Americans; however, few studies have focused on the barriers and facilitators to eating F\&V for low-income Tucsonans [9-12].

Farmers' markets (FM) are increasingly viewed as a potential strategy to increase access to and consumption of fruits and vegetables, which would decrease risk of chronic disease [13]. Because of the promise that FM hold for improving access to healthy foods in underserved areas, Community Food Bank of Southern Arizona (CFBSA) operates two farmers' markets targeted at lowincome Supplemental Nutrition Assistance Program (SNAP) recipients in the Tucson metropolitan area. In the Double Up SNAP incentives program, SNAP recipients can use Electronic Benefit Transfer (EBT) cards to purchase produce, so that the benefits 
can be used at local markets. Cooking demonstrations were also offered to learn about the selection and preparation of seasonal produce. However, there is little published literature to document the direct relationship between shopping at FM and increased F\&V consumption, although some evidence exists for effectiveness [14-16].

Previous studies have documented the characteristics of people who use farmers' markets, often finding that farmers' market customers tend to be of higher socioeconomic status when compared to the general population [17,18]. However, less is known about specific socio-demographic characteristics of farmers' market customers who are SNAP recipients in Southern Arizona communities, and how to encourage lower-income residents to use farmers' markets. In prior work, SNAP sales account for less than 3\% of the total farmers' market revenue, indicating that considerable barriers exist to these efforts. In addition, little is known about the facilitators to farmers' market shopping. Thus, more information is needed about potential customers and their interaction with farmers' markets. Therefore, the aims of this study were to (1) describe socio-demographic characteristics and frequency of F\&V consumption of participants; (2) examine barriers and facilitators to farmers' market shopping and F\&V consumption in low-income communities; and (3) examine associations between farmers' market use, with the outcomes of F\&V consumption.

\section{Materials and Methods}

\section{Study design, target population and setting}

This is a cross-sectional analysis of baseline data from the Double-Up SNAP program (DUSP) study. DUSP is an ongoing intervention trial operating at multiple levels by the Community Food Bank of Southern Arizona (CFBSA) to improve access to and consumption of F\&V in SNAP recipients in Pima County, a USDA strike Force zone. Baseline data were collected from July to September 2016. Participants were adults actively recruited at two locations accessible to low-income residents. Eligibility criteria for participation included being over 18 years of age, a Pima County resident, and one of the primary food shoppers in the household. Exclusion criteria were less than 18 years of age, and not a Pima County resident or SNAP participant.

\section{Data collection}

Eight data collectors were trained on enrolling, consenting, and general questionnaire techniques. In-class practice, role-play, observation, and feedback of data collectors from the lead investigator (HA) were used. Informed consent was gathered from the participants. Following the interviews, data were checked for inconsistencies and other anomalies to improve data quality. Data collectors were provided with constructive feedback on completing the questionnaires during the data collection. All data collection questions and issues were handled on a weekly basis with HA. This study was approved by the Institutional Review Boards of University of Arizona. The study came under the "exempt" category of the regulations for research involving human subjects because it was conducted as part of an evaluation of a service project to improve the program.

To accomplish this study, all farmers' market (FM) customers using EBT cards were surveyed along with a random sample of primary household (non-FM) food shoppers. For the FM customers, interviewers were stationed at an information table, approaching all eligible shoppers over the age of 18 years who had made market purchases that day, potential participants in the markets, asking about their interest in participating, and offering a $\$ 5$ gift token as incentive for completion. As for the random SNAP participants (non-FM) recruited in the waiting room of CFBSA main warehouse, interviewers approached every third person checking in at the CFBSA front desk, explained the purpose of the survey, and then asked individuals whether they would like to participate. If potential participants were interested, the survey instrument was administered. Due to the logistical challenges of conducting surveys in public places and the varying degrees of customer traffic, we did not gather information on the number of persons invited to participate and those who agreed or did not agree to participate. Thus, no response rate is reported.

\section{Survey Measures}

All data were collected using a 32-questions pilot-tested survey addressing behaviors, barriers, and facilitators to F\&V consumption and FM usage. It also included a series of demographic information, and questions about consumption and purchasing of F\&V.

\section{Demographics and behavior}

Race was assessed with one question: "What is your race?" and responses were selected from the following options: White, Black or African American, Asian, Native Hawaiian or other Pacific Islander, American Indian or Alaskan Native, or other. Other demographic data collected included gender (male, female, and other), age (18-29; 30-41; 42-53; 54-64; 66 and older), education (Bachelor; Associates, some college, High school or GED; and other), and primary language spoken (English, Spanish, and other).

\section{Farmers' market perceived access and use}

Farmers' market use was assessed using one question: "How often do you usually shop at this market?" Farmers' market perceived access was measured by asking 2 questions: 1 "How long does it take you to get this market" (in minutes) and 2 "What kind of transportation do you usually use to get to this market." Ten possible scenarios for enhancements to FM including convenient location, affordable price, variety of products, good service, convenient hours of operation, and acceptance of EBT cards were 
provided to farmers' market customers only regarding factors related to shopping at FM. Potential barriers to F\&V purchasing were also assessed among all respondents and included price, lack of available healthy options, knowing about what foods are healthy, preparations and conservations, taste preference, transportation, hours open, and lack of nearby options.

\section{Fruit and vegetable consumption}

F\&V intake information was collected using the risk factor surveillance system (BRFSS) which included only frequencies of fruit or vegetable and not portion size [8]. Respondents were asked how many times per day, week or month they consumed $100 \%$ pure fruit juices, fresh, frozen or canned fruits, cooked or canned beans, dark green vegetables, orange-colored vegetables, and other vegetables over the previous month. Reported daily frequencies of each fruit or vegetable were calculated by dividing weekly frequencies by seven and monthly frequencies by 30 . Then, a composite daily frequency of fruit was calculated based on the sum of the 2 items while the composite daily frequency of vegetables from the 4 types of vegetables.

\section{Statistical analysis}

All analyses were completed using STATA version 14. Differences between socio-demographic and frequency of fruit and vegetable consumption were examined between farmers' market customers and the random primary food shoppers. Chi-square tests were used to examine differences between subgroups percentage and Median test for F\&V consumption (Aim 1). Frequencies and medians were also calculated to describe FM customers shopping practices and barriers to buying fruits and vegetables (Aim 2). A current farmers' market user was defined as anyone who reported using a farmers' market at least 2-3 times a month. Associations between the independent variable of farmers' market use and dependent variables of fruit and vegetable consumption were examined in separate linear regression models (Aim 3). All analyses were adjusted for age, gender, race, and education level. Statistical significance was set at $\mathrm{P}<0.05$.

\section{Results}

\section{Socio-demographic characteristics of participants}

In total, 56 FM customers and 107 non-FM food shoppers were surveyed, and the comparisons of demographic characteristics between both groups showed that FM customers had higher education (college graduate, 37.5\% vs.16.8\%) and tended to be younger (18-41years, 39.3\% vs. 19.6\%) compared to non-FM food shoppers, but were mostly over 42 years old. Compared with non-FM respondents, FM customers were also more likely to be white (66.1\% vs. 43\%), women (73.3\% vs. $72 \%)$, while reporting English as their primary language (91.1\% vs. $73.8 \%)$ (Table 1$)$.

\begin{tabular}{|c|c|c|c|}
\hline \multirow[t]{2}{*}{ Characteristics } & $\begin{array}{l}\text { Farmers' market (FM) customers } \\
\qquad \mathrm{n}=56\end{array}$ & $\begin{array}{l}\text { Random primary food shoppers (non-FM) } \\
\qquad n=107\end{array}$ & \multirow[t]{2}{*}{$\mathrm{P}^{\mathrm{a}}$} \\
\hline & $\%$ & $\%$ & \\
\hline \multicolumn{3}{|l|}{ Gender } & \multirow{3}{*}{ NS } \\
\hline Male & 26.79 & 28.04 & \\
\hline Female & 73.21 & 71.96 & \\
\hline \multicolumn{3}{|l|}{ Age (year) } & \multirow{3}{*}{0.006} \\
\hline $18-41$ & 39.29 & 19.62 & \\
\hline 42 or older & 60.72 & 80.37 & \\
\hline \multicolumn{3}{|l|}{ Race/ethnicity } & \multirow{6}{*}{0.061} \\
\hline White & 66.07 & 42.99 & \\
\hline $\begin{array}{c}\text { Black or African } \\
\text { American }\end{array}$ & 7.27 & 4.67 & \\
\hline Hispanic/Latino & 21.82 & 40.19 & \\
\hline American India & 3.64 & 7.48 & \\
\hline Asian Native Hawaiian & 1.82 & 4.67 & \\
\hline \multicolumn{3}{|l|}{ Primary language } & \multirow{4}{*}{0.020} \\
\hline English & 91.07 & 73.83 & \\
\hline Spanish & 5.36 & 22.43 & \\
\hline Other $^{\mathrm{b}}$ & 3.57 & 3.74 & \\
\hline \multicolumn{3}{|l|}{ Education $^{c}$} & \multirow{3}{*}{0.003} \\
\hline Non-college graduate & 62.50 & 83.18 & \\
\hline College graduate & 37.50 & 16.82 & \\
\hline \multicolumn{3}{|c|}{$\begin{array}{l}\text { aChi-square tests used to examine differences between FM and non-FM. Significant at } \mathrm{P}<0.05 \\
{ }^{\mathrm{b}} \text { Other language: Cebuano, French, German, Czech, Russian, Ukrainian } \\
\text { 'College graduate= Bachelor's degree or higher; Non-college graduate=Less than Bachelor's degree } \\
\text { Table 1: Demographics of Survey Participants }(\mathrm{n}=163)\end{array}$} & \\
\hline
\end{tabular}




\section{Shopping practices among FM customers}

Overall, 44.6\% reported shopping at a farmers' market at least once a week in the past year (Table 2). About 45\% of participants reported living less than a 10-minute car drive from the closest farmers' market but $73.2 \%$ of them used a vehicle to access the closest farmers' market. When asked the likelihood of shopping at FM and awareness of farmers' market promotions, one-third of FM respondents indicated the variety of products, better and fresher produce, and convenient location while only $23.2 \%$ were aware of county-wide efforts to enhance or promote farmers' markets.

\begin{tabular}{|c|c|c|}
\hline & \multicolumn{2}{|c|}{$\begin{array}{l}\text { Farmers' market (FM) customers } \\
\qquad n=56\end{array}$} \\
\hline & $\mathbf{N}$ & $\%$ \\
\hline \multicolumn{3}{|c|}{ Frequency of farmers' market shopping } \\
\hline This is the first time & 7 & 12.50 \\
\hline Every week & 25 & 44.64 \\
\hline Twice a month & 13 & 23.21 \\
\hline Once a month & 7 & 12.50 \\
\hline Every few months & 11 & 19.64 \\
\hline \multicolumn{3}{|c|}{ Distance to the farmers' market } \\
\hline $0-10$ minutes & 25 & 44.64 \\
\hline $11-20$ minutes & 10 & 17.86 \\
\hline 21-30 minutes & 13 & 23.21 \\
\hline More than 30 minutes & 8 & 14.29 \\
\hline \multicolumn{3}{|c|}{ Transportation to the farmers' market } \\
\hline Walk & 6 & 10.71 \\
\hline Bike & 5 & 8.93 \\
\hline Bus/Streetcar & 4 & 7.14 \\
\hline Vehicle & 41 & 73.21 \\
\hline \multicolumn{3}{|c|}{ Respondents' likelihood of shopping at farmers' market } \\
\hline Close to home /work or school & 9 & 16.07 \\
\hline Convenient location & 17 & 30.36 \\
\hline Affordable price & 6 & 10.71 \\
\hline Variety of products & 20 & 35.71 \\
\hline $\begin{array}{l}\text { Preferred products are always } \\
\text { available }\end{array}$ & 8 & 14.29 \\
\hline Better and fresher produce & 19 & 33.93 \\
\hline Good service & 8 & 14.29 \\
\hline Familiarity & 6 & 10.71 \\
\hline Convenient hours of operation & 3 & 5.36 \\
\hline Accept EBT cards & 11 & 19.64 \\
\hline DUSP & 13 & 23.22 \\
\hline
\end{tabular}

DUSP=Double Up SNAP Program

Table 2: Farmers' market Customers Shopping Practices and Likelihood of Shopping

\section{Consumption of fruits and vegetables}

FM customers consumed more fruits (100\% pure fruits juices and fresh, frozen, or canned fruits) compared to non-FM food shoppers, although the difference was not significant (Table 3). Similarly, FM participants consumed more vegetables (dark green vegetables, orange-colored vegetables, and other vegetables), except for cooked or canned beans that were significantly consumed by non-FM participants $(\mathrm{P}=0.03)$. Consequently, daily consumption of fruits (1.0 vs. 0.7$)$ and vegetables (2.4 vs. 1.9$)$ were higher among FM customers compared to non-FM food shoppers. Additionally, fewer FM customers consumed fruits and vegetables less than one time per day compared with non-FM food shoppers (Figure 1). When asked for barriers to fruit and vegetable consumption, the top three reasons reported by FM customers were price, lack of nearby options, and lack of available healthy options while non-FM food shoppers mentioned price, followed by lack of nearby options, transportation, and lack of available healthy options (Figure 2). 


\begin{tabular}{|c|c|c|c|}
\hline & $\begin{array}{l}\begin{array}{l}\text { Farmers' market (FM) customers } \\
\mathrm{n}=56\end{array}\end{array}$ & $\begin{array}{l}\text { Random primary food shoppers (non-FM) } \\
\qquad \mathrm{n}=107\end{array}$ & $\mathbf{P}^{\mathbf{a}}$ \\
\hline & $\%$ & $\%$ & \\
\hline \multicolumn{4}{|c|}{ Consumption of fruits (\%) } \\
\hline $100 \%$ pure fruits juices & 60.38 & 54.29 & NS \\
\hline $\begin{array}{l}\text { Fresh, frozen or canned } \\
\text { fruits }\end{array}$ & 96.43 & 92.45 & NS \\
\hline \multicolumn{4}{|c|}{ Consumption of vegetables (\%) } \\
\hline Cooked or canned beans & 78.57 & 90.57 & 0.034 \\
\hline Dark green vegetables & 96.36 & 88.68 & NS \\
\hline Orange-colored vegetables & 94.55 & 84.11 & 0.056 \\
\hline Other vegetables & 98.18 & 96.26 & NS \\
\hline \multicolumn{4}{|c|}{ Median times consumed daily } \\
\hline Fruits & 1 & 0.74 & 0.061 \\
\hline Vegetables & 2.43 & 1.86 & 0.018 \\
\hline
\end{tabular}

NS: Non-significant $(P>0.05)$

${ }^{a}$ Comparison between FM and non-FM were examined using chi-square tests (\%) and median (median). Significant at $\mathrm{P}<0.05$

Table 3: Frequency of Fruit and Vegetable Consumption by Group

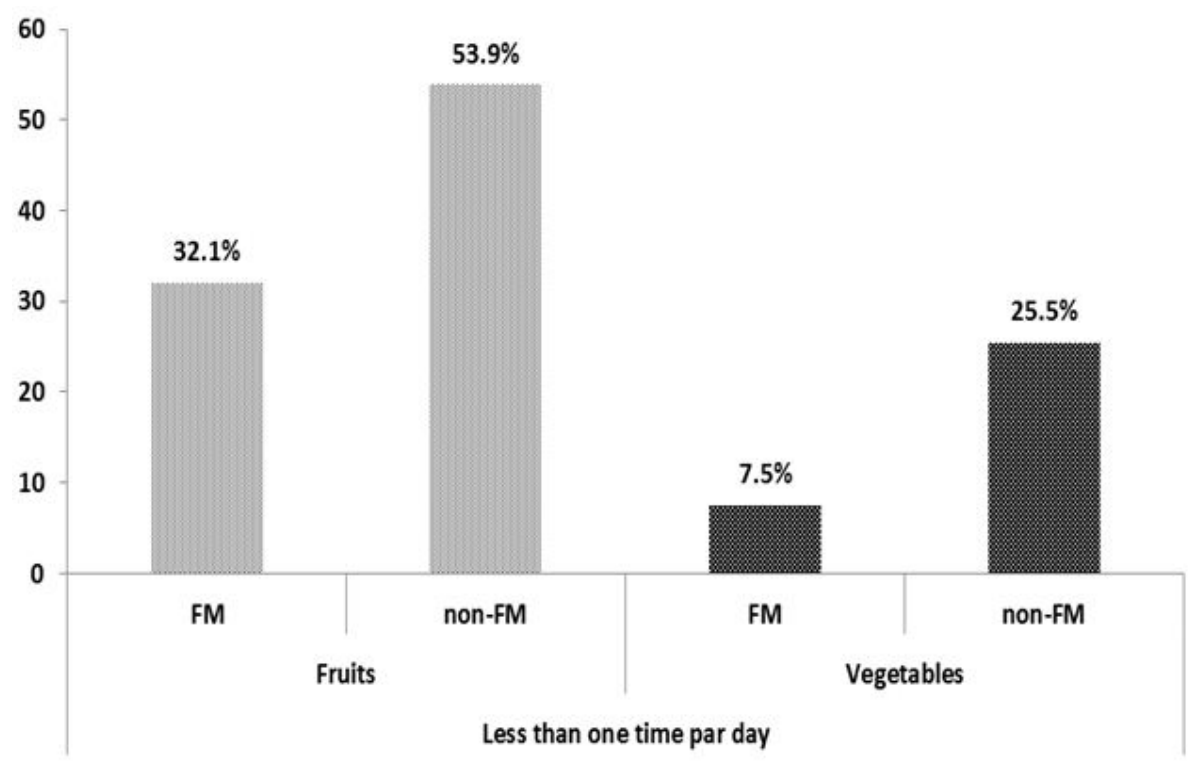

Figure 1: Consumed Fruits and Vegetables less than one time per day

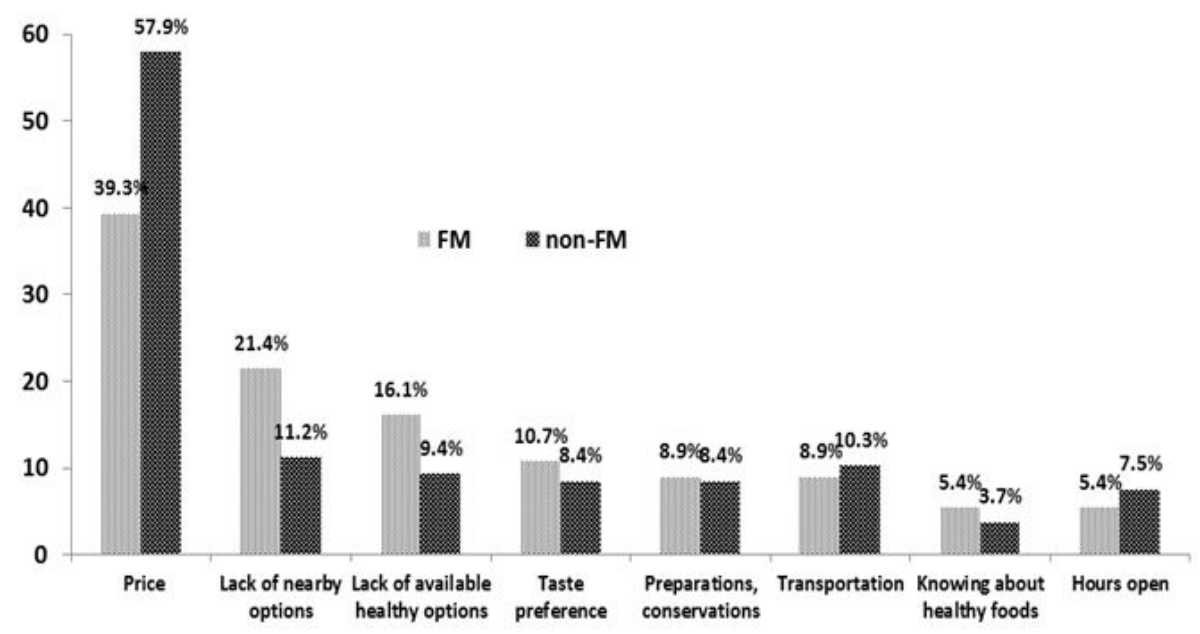

$\mathrm{FM}=$ Farmers' market; non-FM=non-farmers' market

Figure 2: Barriers to Buying Fruits and Vegetables 


\section{Associations between farmers' market use and fruit and vegetable consumption}

In adjusted models with fruit and vegetable consumption as the dependent variable (Table 4), consumption was positively associated with use of farmers' markets (fruits: estimate $=0.36$, standard error $=0.17, \mathrm{p}=0.038$; vegetables: estimate $=0.82$, standard error $=0.35, \mathrm{p}=0.021$ ). This means those who visited a farmers' market at least $2-3$ times a month consumed on average 0.4 times of fruit and 0.8 times of vegetable daily more than those who visited a farmers' market at most once a year.

\begin{tabular}{|c|c|c|c|}
\hline & Coefficient & Stand. Std. Err & $P$ value \\
\hline \multicolumn{4}{|c|}{ Fruits $(n=156)$} \\
\hline Farmers' market use & 0.365 & 0.175 & 0.038 \\
\hline \multicolumn{4}{|c|}{ Vegetables $(n=158)$} \\
\hline Farmers' market use & 0.822 & 0.352 & 0.021 \\
\hline
\end{tabular}

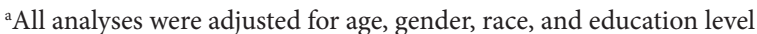

Table 4: Associations between Farmers' market Use and Fruit and Vegetable Consumption ${ }^{\mathrm{a}}$

\section{Discussion}

This study suggests that, similarly to Corner., et al. and Elepua., et al. FM customers are more likely to be white [19,20]. Onianwa., et al. even found that white individuals were 1.8 times more likely to shop at a FM; but these results were not statistically significant [21]. However, Alkon's studies of two demographically and geographically diverse FM from two different neighborhoods found that most customers at one FM were white, whereas the majority at the other FM were black [22,23]. This suggests that the FM use is related to location of individual markets and cultural acceptability of FM in different racial/ethnic groups. As for our results about gender, similar findings were observed in the United States where at least $64 \%$ and up to $77 \%$ of survey respondents reported being female [20,24-26]. Bellows., et al. explained these findings about gender by the fact that a majority of females were responsible for cooking and food shopping [27]. Bond and colleagues suggested that females might be more apt to complete surveys while French., et al. indicated that the majority of males likely refer primary food shopping responsibilities to women $[28,29,30]$.

Similar to the present study, several studies concluded that the average FM customer was over 40 years of age, although Velasquez et al. found an average customer age of 34 years [19-21,25,31]. It is possible that older community members use FM for social reasons in addition to health-consciousness, since Hunt's review found that increased age was significantly related to more frequent social interactions [32]. According to Bellows and colleagues, both male and female consumers over 42 years of age were more likely to support natural food attributes found at the FM [27]. Our study analysis also indicated that both FM attracted college graduate individuals. Other on-site surveys confirmed these findings, with 60\% to $94 \%$ of respondents attaining at least some level of college education $[20,21,26,33]$. However, Varner and Otto found no significant differences in sales at FM where educational attainment was lower than the surrounding US Census area [31]. Therefore, research is needed to better understand divergent findings about the education of farmers' market shoppers.

The results also highlight agreement related to facilitators and barriers to FM use. Indeed, among past studies that included lowincome populations, food quality and food variety were identified as being important factors for using FM [34]. However, similar to Jilcott., et al. in Pitt County (NC) where 17\% of SNAP residents shopped at a FM, only 56 FM customers were interviewed in the present study, suggesting that more work is needed to encourage SNAP residents to shop at FM in this community [33]. Furthermore, the low percentage of participants reporting affordable price, preferred products, good service, and convenient hours of operation coupled with lack of awareness, may present barriers to use of FM. Although the community where our study was conducted is diverse with a strong Hispanic culture, only $22 \%$ of FM customers were Hispanic/Latino, suggesting that FM may not be adequately capturing the perspectives of specific subpopulations. Cultural barriers will therefore need to be bridged to attract the Latino consumers [19]. Finally, according to Alia., et al. key personal facilitators of FM use were the opportunity to access information and resources related to food preparation [35]. However, the cooking demonstration was not associated with support for FM in this study, suggesting efforts are needed to increase residents' awareness of activities at the FM.

In the present study, FM customers had a low F\&V intake, although their consumption was greater than non-FM food shoppers. Indeed, using the scoring procedure by Moore., et al. only $12.5 \%$ of all respondents met fruits intake recommendations, and $14 \%$ met vegetable recommendations [18]. These results reinforce the need to increase F\&V consumption in low-income populations [1-3]. Moreover, similar to this study's findings, shopping at FM was positively associated with F\&V consumption in North Carolina, DC and in Florida among WIC participants [13,36-38]. Thus, increasing access to FM may be a particularly effective strategy to improve F\&V consumption among low-income populations. However, consistent with national studies, prices, lack of nearby options, lack of available healthy options, and transportation were reported as the main barriers to F\&V consumption in the present study $[39,40]$. Therefore, substantial new efforts are needed to build consumer demand for F\&V through competitive pricing, location, nutrition education, and promotion of FM. 
One limitation of this study is that self-reports of intake were based on a limited set of questions and were prone to measurement error and recall bias. Another limitation is the small sample size of FM customers. Nonetheless, this study provides insight into important barriers and facilitators to using FM for low-income families receiving government assistance. However, these findings may have limited generalizability to other states or low-income individuals not receiving government assistance. Responses for the question regarding how often the respondents consumed fruits and vegetables locally grown from a farmers' market may also vary by the season in which the surveys were conducted, and may lead to an underestimation or an overestimation of the 12-month average. However, despite this limitation, the study used the validated Block Fruit and Vegetable Screener. Other strength of this study was the examination of low-income populations, including diverse, southwestern populations, which have not been studied in farmers' market research.

\section{Conclusion}

F\&V consumption was positively associated with FM shopping, suggesting that FM may be a viable method to increase produce consumption in low-income populations. In particular, results point out that local farmers have successfully created a quality image of their products since this is one of the most important draw to consumers. Consequently, these high product standards must be diligently maintained. In addition to breaking down economic, service delivery, social and personal barriers to FM usage, there is a need to disseminate information promoting availability of FM and specific features of those markets such as incentive program and types of payment accepted.

The results from this study provide guidance for future research, policy, and practice to increase the use of FM as a strategy to promote healthy diet. They could aid in the development of a social marketing campaign to promote the purchase of F\&V at local farmers' markets among low-income consumers. Emphasizing the benefits related to nutritional quality, and freshness of locally grown farmers' market produce may help messages resonate with consumers. This study's findings can also assist in planning and evaluating the USDA FINI Grant Project's farmers' market initiative, which has the goals of starting new farmers' markets and making enhancements to farmers' markets that could include increasing transportation to/from markets, and implementing SNAP EBT cards at markets. However, these enhancements must be coupled with increased market promotion activities. Finally, the knowledge gained from such an evaluation can also be shared with other FINI Grant-funded states.

\section{Acknowledgments}

The authors gratefully acknowledge the support of USDA Food Insecurity Nutrition Incentive (FINI) Grant Program (Award number: GRANT12057035), and expertise of Drs. Taren Douglas and Sheila Parker in the Health Promotion Sciences Department of the University of Arizona. They also thank the willing farmers' market customers and county residents surveyed for their participation. They wish to express their very special appreciation to volunteers whose contribution was central to this project.

\section{References}

1. Boeing H, Bechthold A, Bub A, Ellinger S, Haller D, et al. (2012) Critical review: Vegetables and fruit in the prevention of chronic diseases. Eur J Nutr 51: 637-63. 2. Oguntibeju OO, Esterhuyse AJ, Truter EJ (2013) The role of fruit and vegetable consumption in human health and disease prevention. INTECH Open Access Publisher.

3. US Department of Health and Human Services and US Department of Agriculture (2015) 2015-2020: Dietary guidelines for Americans (8th edn).

4. Stringhini S, Sabia S, Shipley M, Brunner E, Nabi H, et al. (2010) Association of socioeconomic position with health behaviors and mortality. JAMA 303: 115966.

5. Lin B (2005) Diet quality usually varies by income status. Amber Waves 3: 4-5.

6. Centers for Disease Control and Prevention (2010) State-specific trends in fruit and vegetable consumption among adults-United States, 2000-2009. MMWR Morb Mortal Wkly Rep 59: 1125-30.

7. National Center for Chronic Disease Prevention and Health Promotion (2009) The power of prevention: Chronic disease ... the public health challenge of the 21st century. Atlanta, GA: Centers for Disease Control and Prevention.

8. Centers for Disease Control and Prevention, National Center for Chronic Disease Prevention and Health Promotion, Division of Population Health (2016) BRFSS prevalence \& trends data.

9. Yeh MC, Ickes SB, Lowenstein LM, Shuval K, Ammerman AS, et al. (2008) Understanding barriers and facilitators of fruit and vegetable consumption among a diverse multi-ethnic population in the USA. Health Promot Int 23: 42-51.

10. Boyington JE, Schoster B, Martin KR, Shreffler J, Callahan LF (2009) Perceptions of individual and community environmental influences on fruit and vegetable intake, North Carolina, 2004. Prev Chronic Dis 6: A04.

11. Haynes-Maslow L, Auvergne L, Mark B, Ammerman A, Weiner BJ (2015) Low-income individuals' perceptions about fruit and vegetable access programs: A qualitative study. J Nutr Educ Behav 47: 317-324.

12. Trude AC, Kharmats AY, Hurley KM, Steeves EA, Talegawkar SA, et al. (2016) Household, psychosocial, and individual-level factors associated with fruit, vegetable, and fiber intake among low-income urban African American youth. BMC Public Health 16: 872.

13. Pitts SB, Gustafson A, Wu Q, Mayo ML, Ward RK, et al. (2014) Farmers' market use is associated with fruit and vegetable consumption in diverse southern rural communities. Nutr J 13: 1 .

14. Gorham G, Dulin-Keita A, Risica PM, Mello J, Papandonatos G, et al. (2015) Effectiveness of fresh to You, a discount fresh fruit and vegetable market in lowincome neighborhoods, on children's fruit and vegetable consumption, Rhode Island, 2010-2011. Prev Chronic Dis 12 : E176.

15. Young CR, Aquilante JL, Solomon S, Colby L, Kawinzi MA, et al. (2013) Improving fruit and vegetable consumption among low-income customers at farmers markets: Philly Food Bucks, Philadelphia, Pennsylvania, 2011. Prev Chronic Dis 10: E166. 
16. Olsho LE, Payne GH, Walker DK, Baronberg S, Jernigan J, et al. (2015) Impacts of a farmers' market incentive programme on fruit and vegetable access, purchase and consumption. Public Health Nutr 18: 2712-21.

17. Byker C, Shanks J, Misyak S, Serrano E (2012) Characterizing farmers' market shoppers: A literature review. J Hunger Environ Nutr 7: 38 -52.

18. Moore LV, Thompson FE (2015) Adults meeting fruit and vegetable intake recommendations_-United States, 2013. MMWR Morb Mortal Wkly Rep 64: 70913.

19. Conner D, Colasanti K, Ross RB, Smalley SB (2010) Locally grown foods and farmers markets: Consumer attitudes and behaviors. Sustainability 2: 742-756.

20. Elepua G, Mazzocco M (2010) Consumer segments in urban and suburban farmers markets. Int Food Agribus Manag Rev 13: 3-14.

21. Onianwa O, Wheelock G, Mojica M (2005) An analysis of the determinants of farmer-to-consumer direct-market shoppers. J Food Distrib Res 36: 132-34.

22. Alkon AH (2008) From value to values: Sustainable consumption at farmers markets. Agric Hum Values 25: 487-98.

23. Alkon AH (2008) Paradise or pavement: The social constructions of the environment in two urban farmers' markets and their implications for environmental justice and sustainability. Local Environ 13: 271-89.

24. Baker D, Hamshaw K, Kolodinsky J (2009) Who shops at the market? Using consumer surveys to grow farmers' markets: Findings from a regional market in northwestern Vermont. J Extension 47: 1-9.

25. Velasquez C, Eastman C, Masiunas J (2005) An assessment of Illinois farmers' market patrons' perceptions of locally-grown vegetables. J Veg Sci 11: 17-26.

26. Wolf M, Spittler A, Ahern JA (2005) Profile of farmers' market consumers and the perceived advantages of produce sold at farmers' markets. J Food Distrib Res 36: 192-201.

27. Bellows AC, Alcaraz VG, Hallman WK (2010) Gender and food, a study of attitudes in the USA towards organic, local, US grown, and GM-free foods. Appetite 55:540-50

28. Bond JK, Thilmany D, Bond CA (2006) Direct marketing of fresh produce: Understanding consumer purchasing decisions. Choices 21: 229-236.

29. French SA, Wall M, Mitchell NR (2010) Household income differences in food sources and food items purchased. Int J Behav Nutr Phys Act 7: 3-7.

30. French SA, Wall M, Mitchell NR, Shimotsu ST, Welsh E (2009) Annotated receipts capture household food purchases from a broad range of sources. Int J Behav Nutr Phys Act 6: 6

31. Varner T, Otto D (2008) Factors affecting sales at farmers' markets: An Iowa study. Appl Econ Perspect Policy 30: $178-87$.

32. Hunt AR (2007) Consumer interactions and influences on farmers' market vendors. Renew Agric Food Syst 22: 54-66.

33. Jilcott SB, Wall-Bassett ED, Moore JB, Sharkey JR (2011) Use of traditional and nontraditional food venues among female participants in the supplemental nutrition assistance program (SNAP). J Hunger Environ Nutr 6: 64-74.

34. Freedman DA, Vaudrin N, Schneider C, Trapl E, Ohri-Vachaspati P, et al. (2016) Systematic review of factors influencing farmers' market use overall and among low-income populations. J Acad Nutr Diet 116: 1136-55.

35. Alia KA, Freedman DA, Brandt HM, Browne T (2014) Identifying emergent social networks at a federally qualified health center-based farmers' market. Am J Community Psychol 53: 335-45.

36. Pitts SB, Wu Q, McGuirt JT, Crawford TW, Keyserling TC, et al. (2013) Associations between access to farmers' markets and supermarkets, shopping patterns, fruit and vegetable consumption, and health indicators among women of reproductive age in eastern North Carolina. Public Health Nutr 16: 1944-52.

37. Racine EF, Vaughn AS, Laditka SB (2010) Farmers' market use among African-American women participating in the special supplemental nutrition program for women, infants, and children. J Am Diet Assoc 110: 441-446.

38. Grin BM, Gayle TL, Saravia DC, Sanders LM (2013) Use of farmers markets by mothers of WIC recipients, Miami-Dade county, Florida, 2011. Prev Chronic Dis 10: E95.

39. Reicks M, Randall JL, Haynes BJ (1994) Factors affecting consumption of fruits and vegetables by low-income families. J Am Diet Assoc 94: 1309-11.

40. Leone LA, Beth D, Ickes SB, MacGuire K, Nelson E, et al. (2012) Attitudes toward fruit and vegetable consumption and farmers' market usage among lowincome North Carolinians. J Hunger Environ Nutr 7: 64-76.

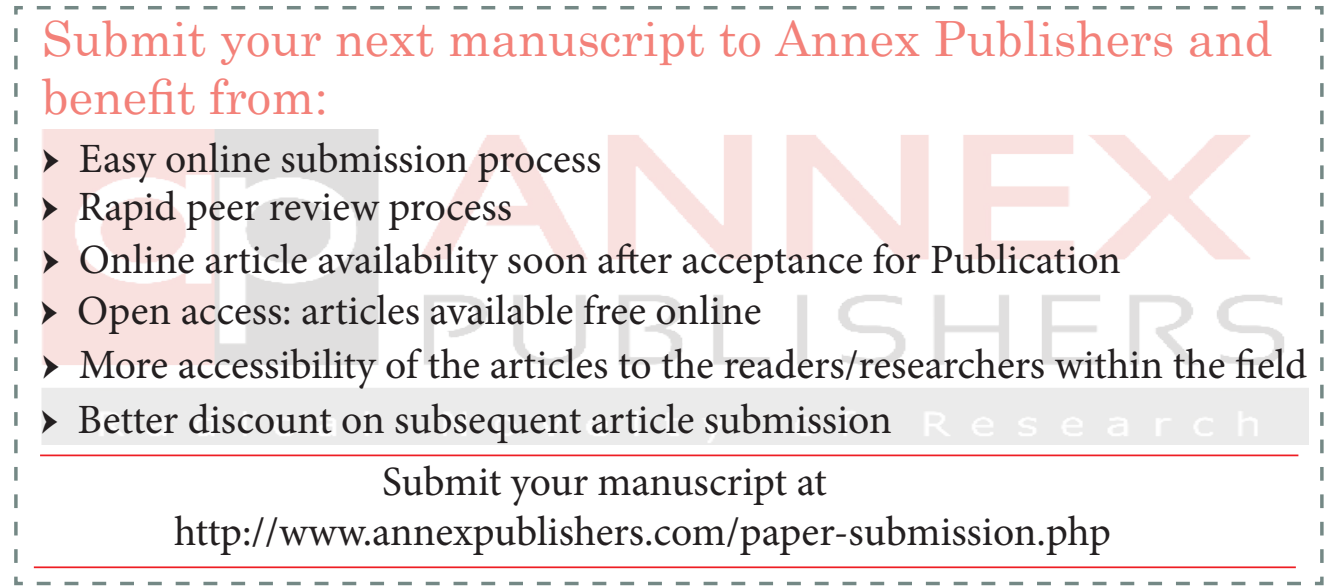

